\title{
A Visit to the Wildlife Refuges on the Gulf of Mexico
}

by Fred G. Bard, Saskatchewan Museum of Natural History

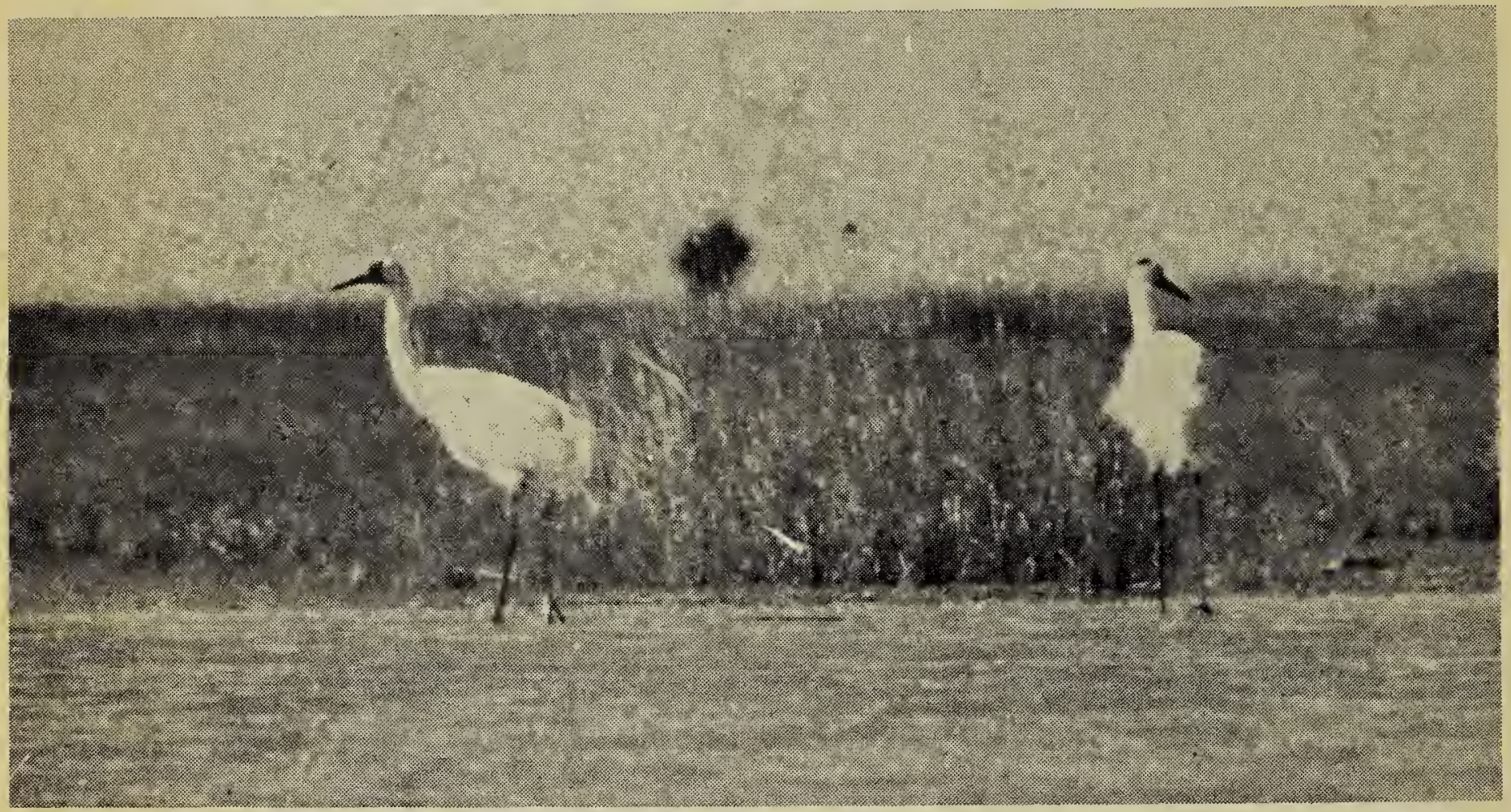

Whooping Cranes at the Aransas Refuge

Photo by F. W. Lahrman

In the latter part of February and early part of March, Fred Lahrman and I visited several of the wildlife refuges on the Gulf of Mexico. The principal reason for our trip was to see the Whooping Cranes at home: the captive birds at the Audubon

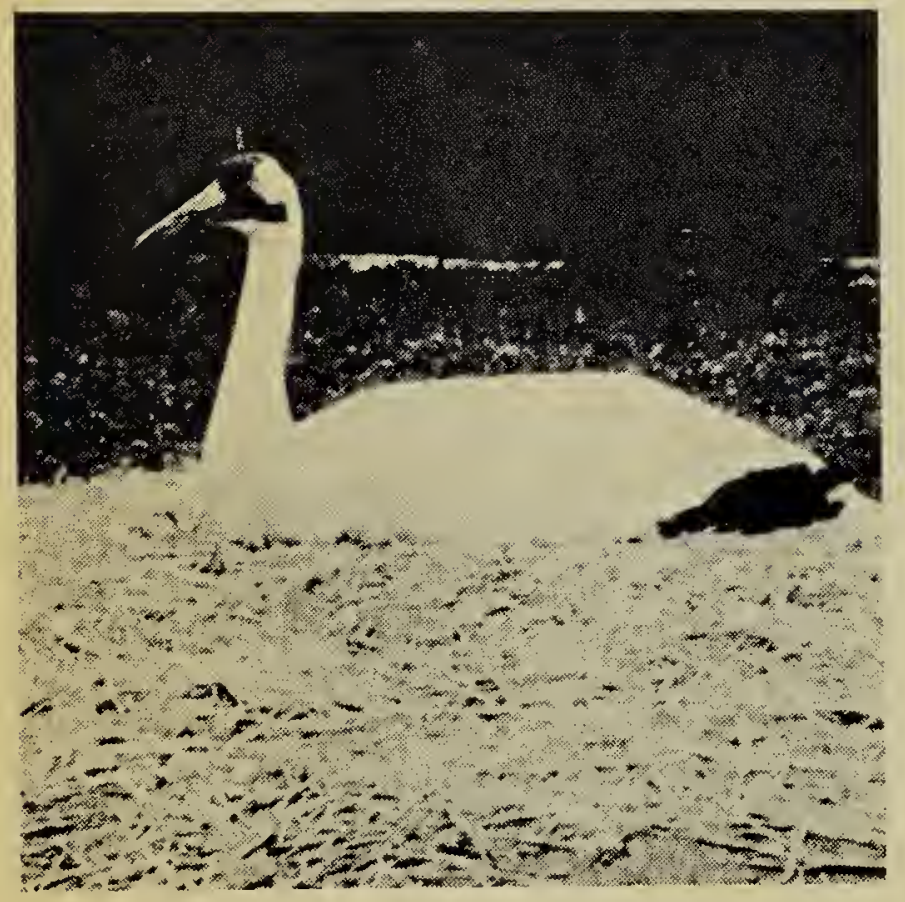

Photo by F. W. Lahrman Captive Whooping Crane Audubon Park Zoo
Park Zoo at New Orleans, the single bird at the San Antonio Zoo, and the wild flock at Austwell, Texas, on the Aransas National Wildlife Refuge. We left Regina at $7.00 \mathrm{a} . \mathrm{m}$. on February 19, a clear, cold morning following a night of $-20^{\circ}$. We were held up by a severe snowstorm at Griswold, Iowa, then continued our journey through the beautiful Ozarks and along the Mississippi. The load of ice under our car was not completely melted until we were on the lower Mississippi near Jackson.

We saw the first Whooping Cranes on February 24 at the Audubon Park Zoo in New Orleans where we were met by Mr. George Douglas, the Secretary-Manager of the Park, and his assistant, Mr. Russell, whose personal responsibility is to attend to the needs of the Whooping Cranes. We were given every opportunity to photograph the five Whooping Cranes in this interesting and very beautiful park zoo, so we took a number of photographs although the light was poor. The captive birds seemed in excellent health and quite content with their quarters. We were very impressed with 
the zoo's success as we looked on the nesting pair of birds with their single egg. The first two eggs had been collected and placed in an incubator, and the birds took turns incubating the remaining egg, leaving the nest to feed and drink and to preen their feathers and stand guard until it was time to resume nest duty.

The pen is not open to the public, although people may watch the birds from a distance of possibly 60 or 70 feet. A wealth of data is collected by the three attendants who observe the birds around the clock from a small "guard's building" some thirty or forty feet away. The change of incubation duty is carefully recorded to the second as well as the feeding habits and other behaviour. The pair of birds voiced strong disapproval of a low-flying plane going over, but otherwise everything seemed quite serene in this unique enclosure.

Thanking our hosts at the Audubon Park Zoo for their wonderful understanding and co-operation in our quest to learn more of the Whooping Crane, we went on to the Rockefeller Wildlife Refuge at Grand Chenier, Louisiana. Mr. Yan-

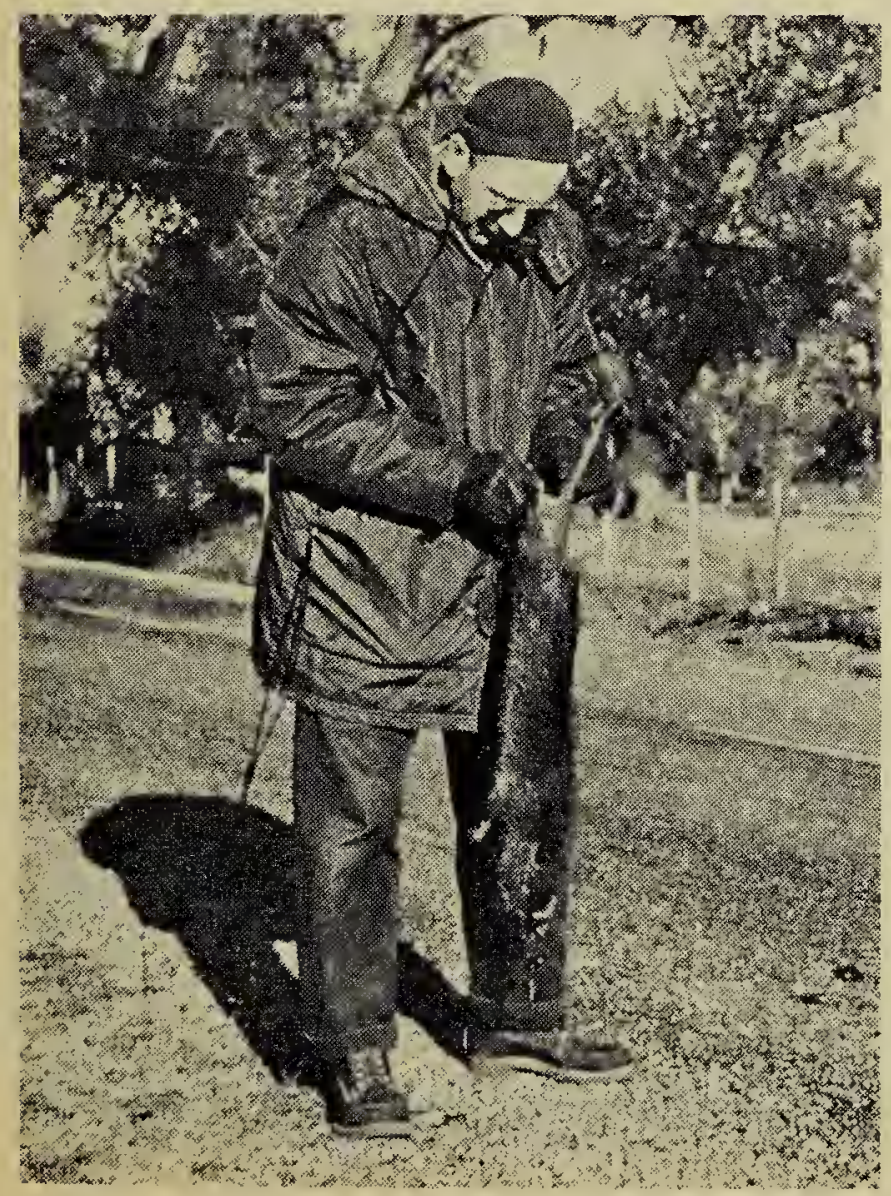

Photo by F. W. Lahrman Author examining Nutria, Rockefeller Refuge

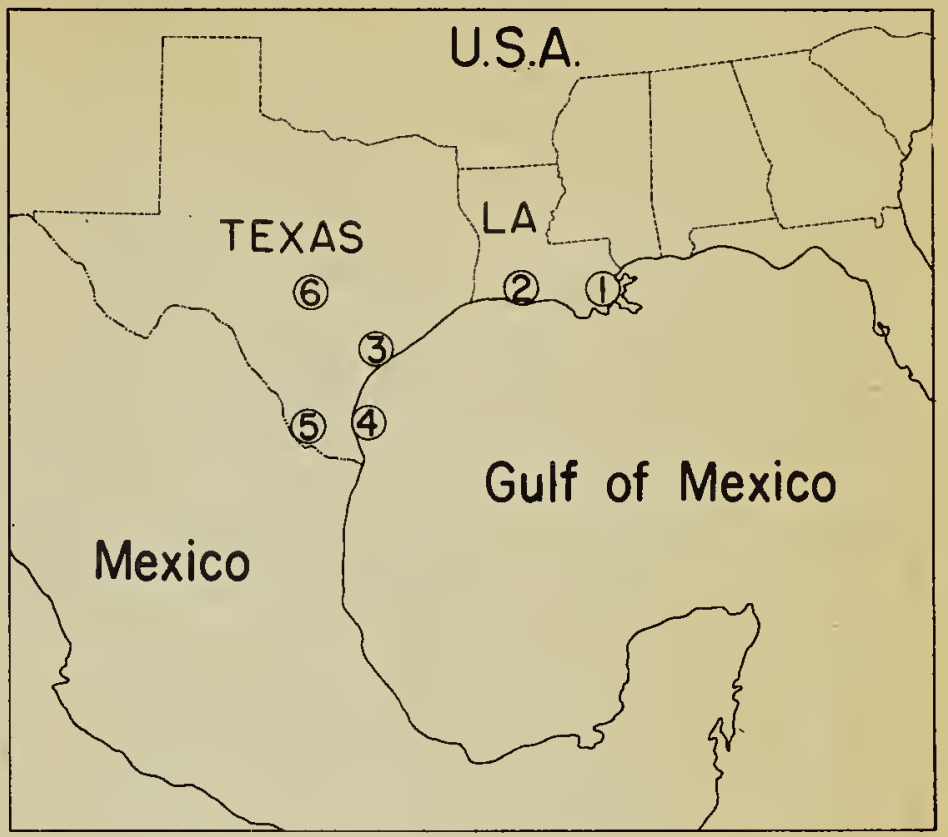

Refuges and park zoos visited

1. New Orleans.

2. Rackefeller Wildlife Refuge.

3. Aransas National Wildlife Refuge.

4. Laguna Atascosa National Wildlife Refuge.

5. Santa Ana National Wildlife Refuge.

6. San Antonio.

cey, in charge of refuges for the U.S. Fish and Wildlife Service, arranged with Mr. Ned Crane, the Refuge Manager, for a tour of the refuge and provided us with accommodation in the Research Quarters. The outstanding features of this refuge that we noticed were the miles of dikes that controlled the water levels and the projects being developed to provide food and protection for the birds. As we travelled many leisurely miles through the refuge to get the mood of the place, Mr. Lahrman and I were able to list many species of birds new to us, almost all of them still in their winter plumage. It was here we noticed the prevalence of the Nutria-the marsh mammal that has become so abundant and appears to be so destructive to the marsh plants, corn and cane crops.

It was at Grand Chenier that we met Mr. Crane's brother who designs and builds "marsh buggies," the unique vehicles used by the oil men in this otherwise inaccessible, low-lying area. We rode on one of these out into the marsh area and were amazed at the smoothness of the ride. We were shown, too, the way the marsh buggy can turn out a furrow for a drainage ditch in a single operation. Mr. Crane's inventive genius was further illustrated 


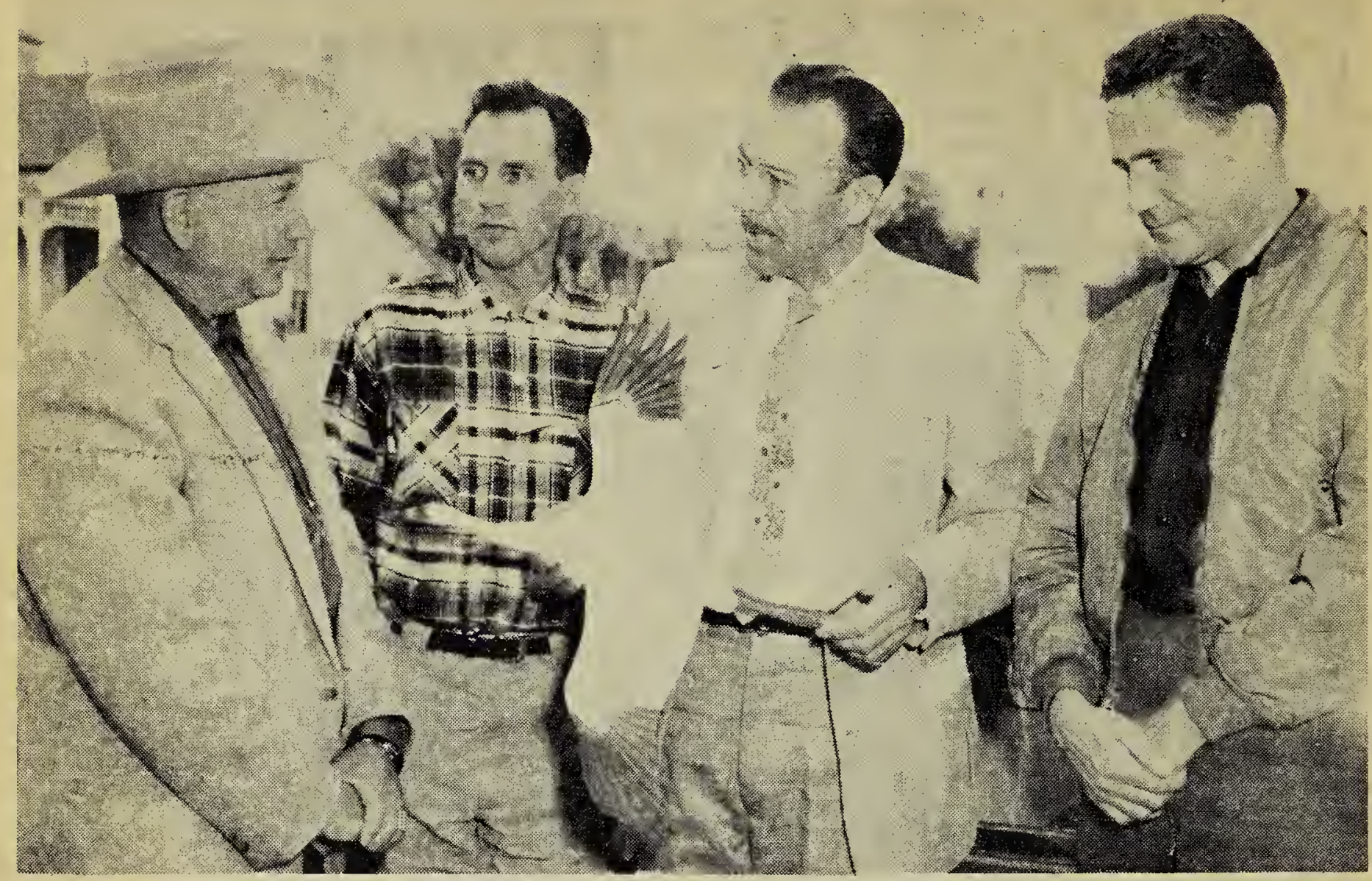

J. Matlock, F. W. Lahrman, F. G. Bard, E. L. Boeker at Victoria, Texas (following flight over the Aransas Refuge)

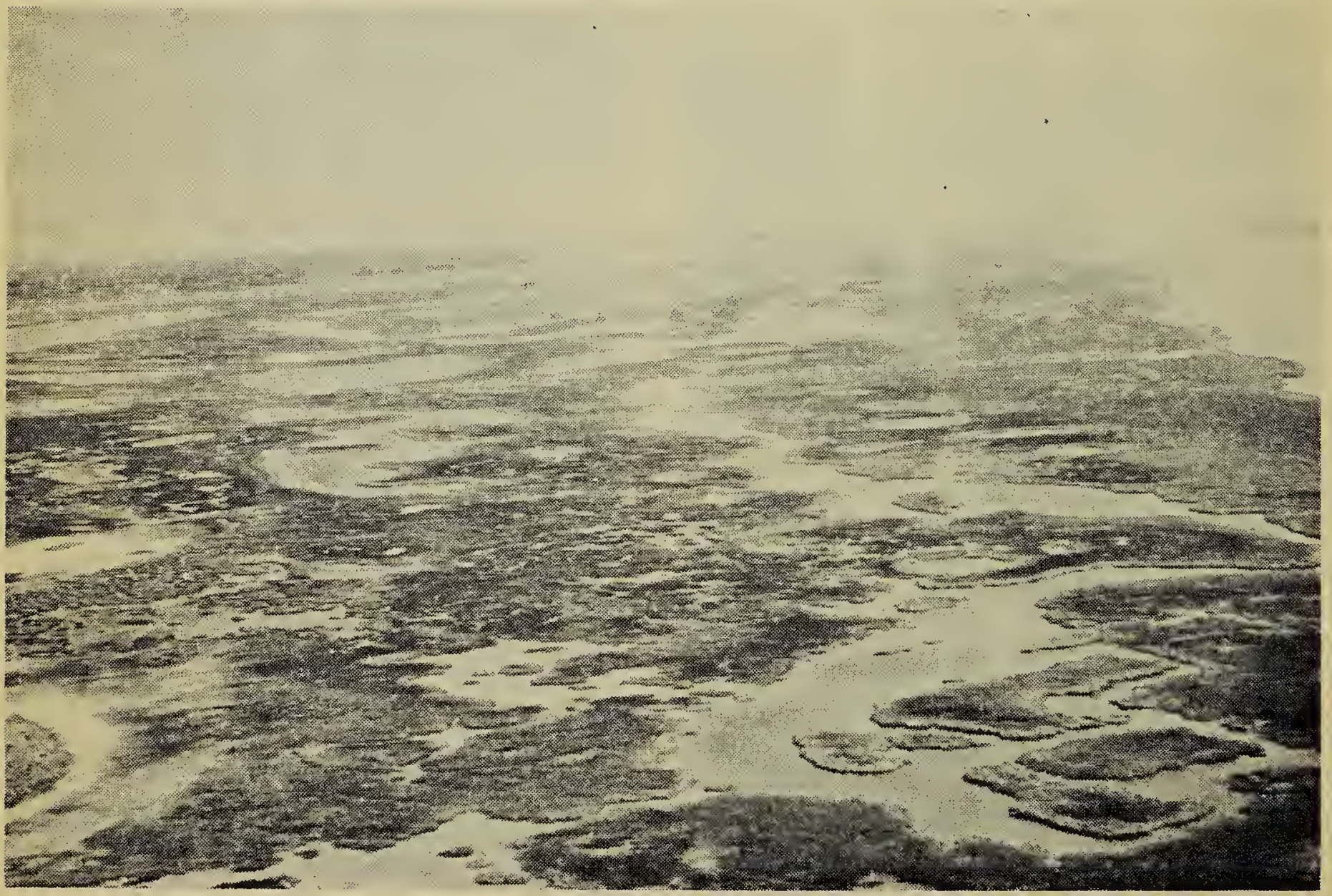

Photo by F. W. Lahrman

Aerial view of wintering grounds of Whooping Crane, Aransas Refuge 


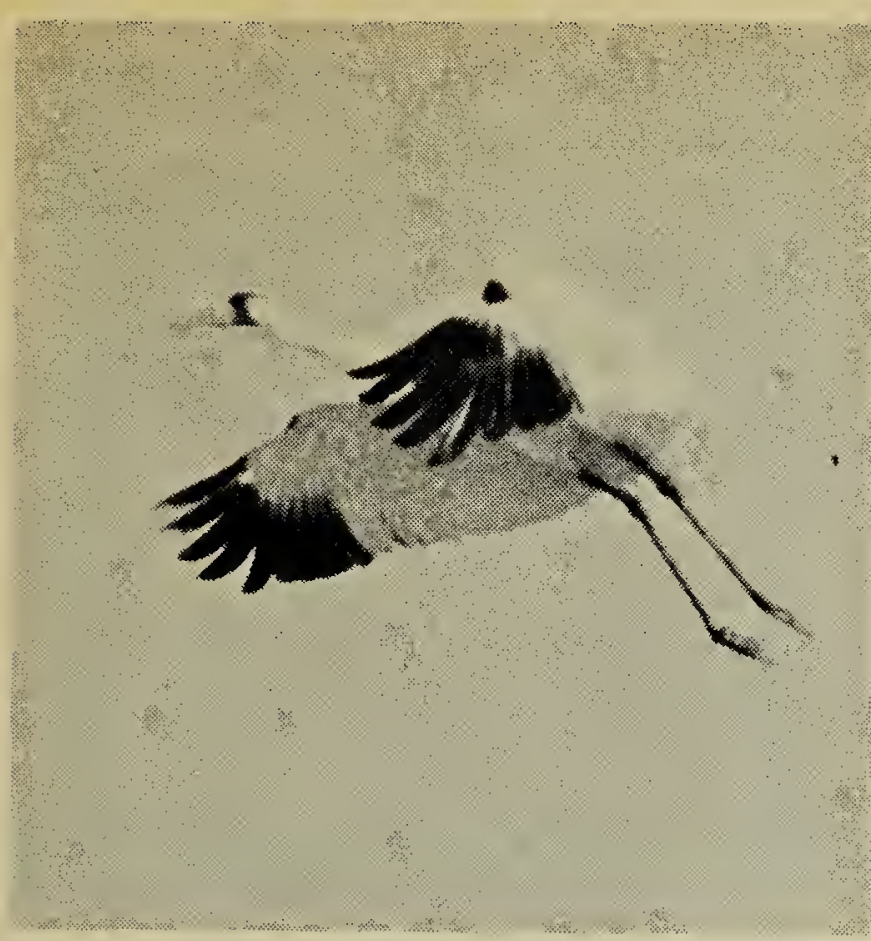

Photo by F. W. Lahrman Whooping Crane over the Aransas Refuge

by the control tower used for the operation of the two-way radios when the vehicles were far from home base. Although it stands nearly 100 feet in height and has no guide wires, the steel tower has withstood the high winds that sometimes occur. When necessary it can be lowered with ease by a single man. It was with reluctance that we left this unique area-the first refuge on our tour-with a promise to return some day to learn more about it.

The next port of call was the A ransas National Wildlife Refuge at Austwell, Texas. On February 28 we arrived at the Befuge to meet Mr. John Johnson, the Refuge Manager, and the Assistant Manager, Robert H. Shield. Here we also met Mr. Art Halloran, the biologist from Cache, Oklahoma, and several others of the Refuge personnel all busy on spring projects. This refuge was very different from the last. It was more extensive and drier, with "tanks" (like our dugouts) built to retain fresh water in the salt flats. Naturally we found different birds and mammals here. We were given a warm welcome and conducted to all parts of the refuge. It was not until March 2 that we had enough sun to photograph the whoopers from a boat on the inter-coastal canal. The birds were located in their regular feeding grounds on the shore of the canal or on the islands. We remained

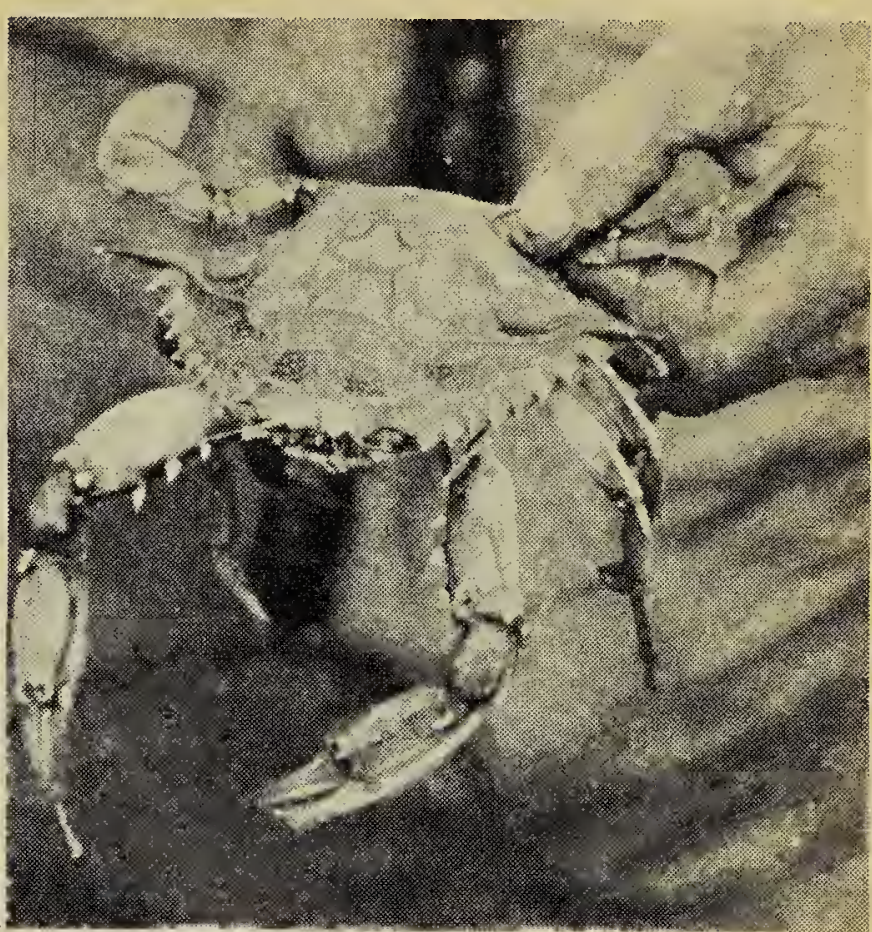

Photo by F. W. Lahrman Blue Crab, food item of the Whooping Cane

in the boat to avoid disturbing the feeding cranes. It was a great thrill to find these birds at last, apparently so content in their winter quarters, and standing out more beautiful than ever in the bright sunshine.

At the Refuge we met Mr. Winston Mair and Dr. David Munro of the Canadian Wildlife Service, along with Mr. C. Williams and Erv Boeker who are working together on the research program for whoopers. On March $4 \mathrm{Mr}$. Lahrman and I accompanied $\mathrm{Mr}$. Boeker and $\mathrm{Mr}$. Matlock (Flyway biologists at Victoria) on an air trip over the refuge and we counted 23 wild Whooping Cranes. We could easily see the difficulty of checking these birds even in a limited refuge area and of knowing the exact day of the birds' arrival and departure. The Aransas National Wildlife Refuge is also a fascinating place for many other species. We saw the courting Wild Turkey gobblers, Armadillos, the Javelinas or Collared Peccary, Raccoons and hundreds of White-tailed Deer.

Moving southward along the Gulf to San Benito, Texas, we met Mr. Leslie Beatty, the Refuge Manager of Laguna Atascosa. We were taken on a conducted tour of the refuge, quite different again from those we had previously visited. We were able to appreciate the amount of work involved in establishing ideal food and water conditions, including 


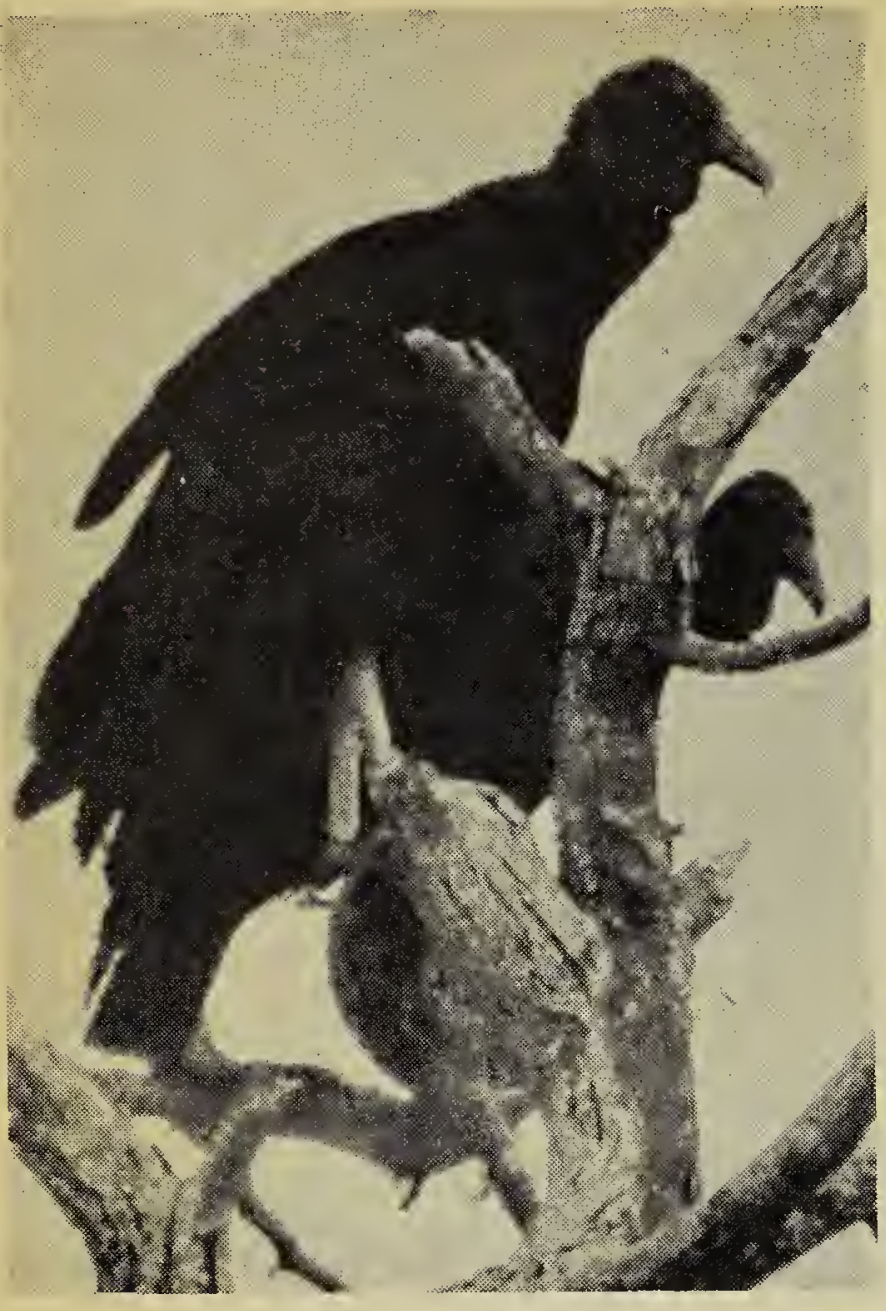

Photo by F. G. Bard

Black Vulture at Laguna Atascosa

the bait crops that were soon eaten up. A quarter of a million Redheads had moved out a few days before our arrival, but a raft of 20,000 were in the bay for us to view on this particular day. We also had the opportunity of seeing the coastal prairies, the salt flats, the low ridges covered with thick, thorny shrubs, brushland composed of mesquite, cacti, and yuccas. I was puzzled by the neat piles of dead brush until Mr. Beatty told us they were Pack Rat homes, each one being built around a cactus.

The Laguna Atascosa National Wildlife Refuge consists of three main water areas-Laguna Atascosa, Laguna de los Patos and Cayo Atascosa. This is the most southerly waterfowl refuge wintering area in the United States. The Christmas Bird Count of 1953 revealed 157 species, and in an eleven-year period (1946-56) 315 species were observed. We expected to see our Sandhill Cranes but they had moved out several days before our arrival. The same afternoon we saw a large specimen of the Texas Diamondbacked Rattlesnake race across the road and disappear in the cover. We could hear the buzzing of its rattles as a note of warning. Visitors are warned to be careful about shaking hands with these strangers!

Later in the day we dined on beautiful Padre Island at one of the modern tourist courts. Through the large windows of the dining room we watched the surf roll in from the Gulf. Padre Island, some 120 miles long, is one of the few remaining places along the Gulf that has undeveloped beach, and there is already pressure to use this lovely beach for commercial development. It is to be hoped that the State will reserve this wonderful natural playground.

The last refuge on our list was the Santa Ana Refuge on the Rio Grande River south of Pharr, Texas. The Refuge Manager, Mr. Fleetwood, assisted us with maps and lists to make the most of our day in this refuge. This area with its tropical-like vegetation was different from the others and we saw birds like the Kiskadee and Vermilion Flycatchers. Perhaps the outstanding sight here was the flock of Black-bellied Tree Ducks resting on a narrow grassy peninsula juttin $;$ into East Lake. Their strange wheezing, whistling calls were repeatedly given as they circled in flight like ibis or cranes. Along one of the trails in the refuge we set up a photographic blind and put out bait. It was not long before 12 Green Jays, as well

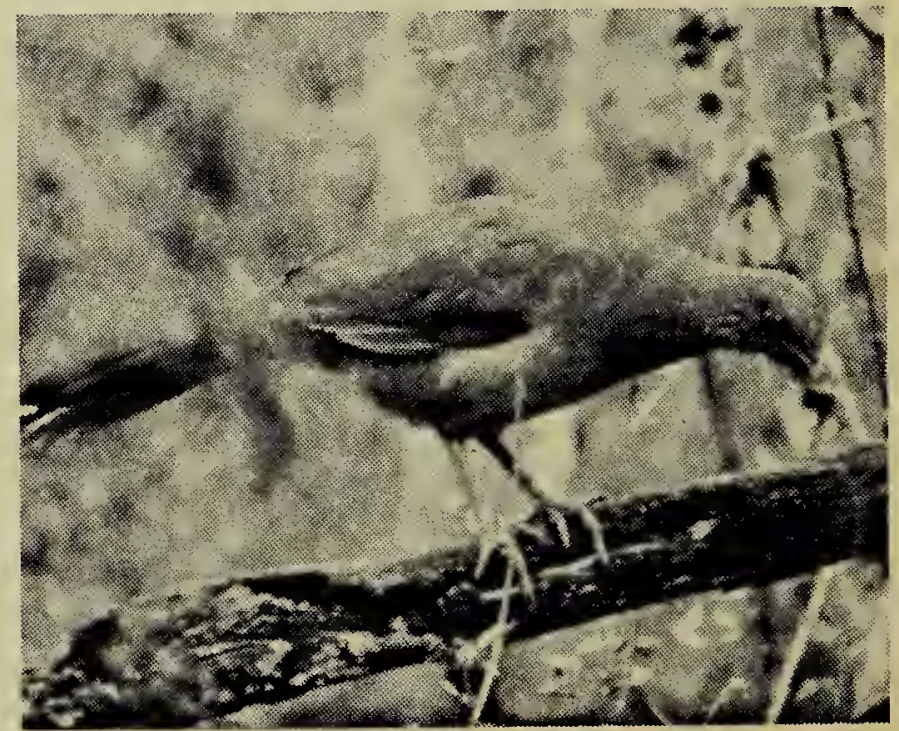

Photo by F. W. Lahrman Chachalaca at Santa Ana 


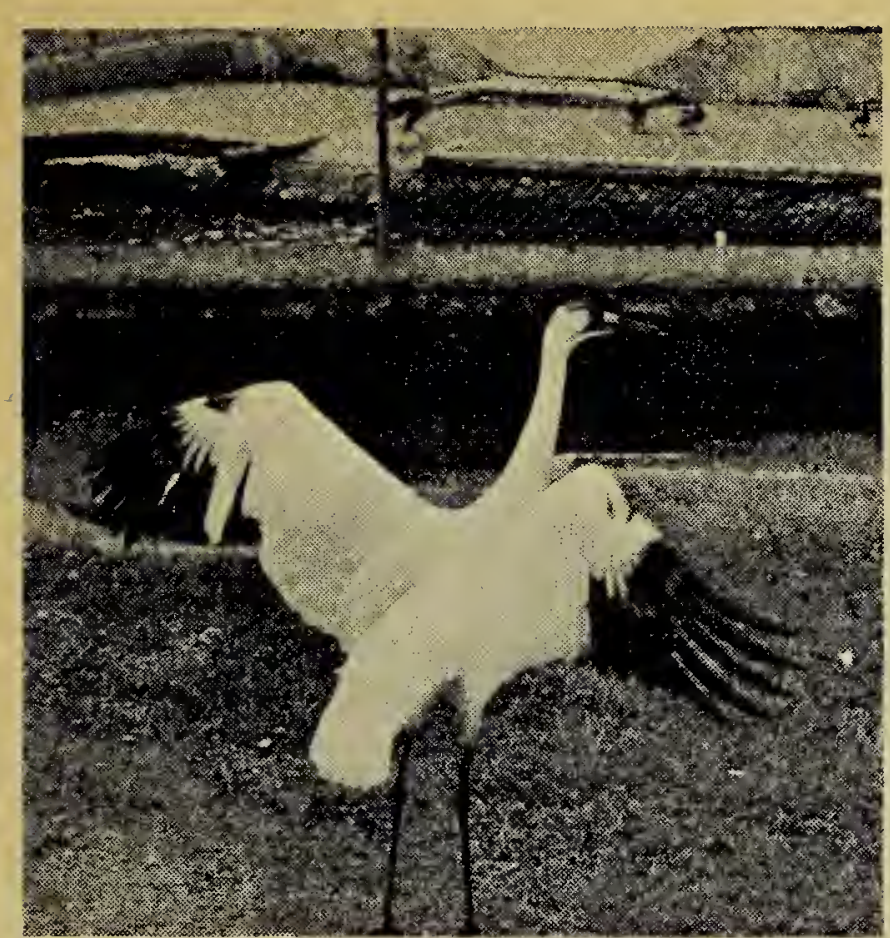

Photo by F. G. Bard Captive bird at the San Antonio Zoo.

as Long-billed Thrashers, Olive Sparrows and Chachalacas appeared. In a flooded grove of trees we saw 35 Anhingas with their wings outstretched drying and preening themselves after a fishing expedition.

In our visits the thing that impressed us most was the value of these refugees and the foresight that has gone into selecting areas that could become useful recreational and study areas for the future. It is interesting to note that many refuges have been established in very recent years in spite of the commercial value of the land because of the necessity of holding such areas if we are to meet adequately the need for sanctuaries. In fact, these areas are essential for the survival of many species. We noticed people from all walks of life coming from long distances to see the unique features of this refuge. All this reminded me that in Saskatchewan we have similar areas called bird sanctuaries and game preserves, that could become very useful refuges. These areas too are interesting and even unique in their plant and animal life, and could become a valuable part of our recreational program. Apart from the fact that water must be stabilized in these areas for a continuing succession of plant and animal life, they require little development. The important thing is to hold the areas so that we can make sure of refuges before it is too late and we have the same problem as the Americans have had in acquiring land for these reserves. The agencies that have set up these refuges along the Gulf are to be congratulated for preserving areas that fill a recreational need and safeguard wildlife research in the future.

The last call on our trip was at the San Antonio Zoo. Here we were met by Mr. Fred Stark, the Manager, and his co-worker Jim Chisholm. In the San Antonio Zoo we saw the single Whooping Crane that was given to Mr. Stark only a few years ago in an emaciated condition. It is now a beautiful, healthy bird living a normal life except for not having a mate. We hope a mate can be provided for this bird without further loss of precious years. The San Antonio Zoo is unique in supplying fresh water and living fish in all the pens so that the birds can live quite normal lives. In fact we saw Pelicans sitting on nests and living as though they were in some of our lakes on the Canadian prairies. Avocets and other beautiful wading birds are here and have in the past nested naturally. We saw the courtship activities of Franklin's Gulls and other gulls and they reminded us of similar activities here on the prairies in the springtime.

We had invitations to visit several other refuges but could not find time to do so. I can only say that these will have top priority for our next trip. Both people and signs along the way said, "Ya'll come back"-and this we certainly intend to do. I should like to urge others too, to visit these refuges- to escape a few weeks of winter, to be awakened by the singing of Mockingbirds and to see our wildlife heritage as it should be.

After visiting these refuges and seeing their tremendous value in protecting wildlife, we are inspired to itry to establish similar refuges in Saskatchewan. Our special thanks go to all of these people who made out trip so very pleasant and you may be sure we wish to accept your invitation to return again. Thank you very much. 